\title{
Radiological and functional changes over 3 years in young children with cystic fibrosis
}

\author{
S.W.J. Terheggen-Lagro, H.G.M. Arets, J. van der Laag and C.K. van der Ent
}

\begin{abstract}
The aim of the present study was to evaluate airway disease progression assessed by chest radiology, expiratory interrupter resistance (Rint,exp) and spirometry in young children with cystic fibrosis (CF) over a 3-yr period.
\end{abstract}

Two chest radiographs combined with two Rint,exp measurements were performed with a 3-yr interval in 21 preschool children (age (mean \pm SD) $3.2 \pm 0.9$ yrs) and 30 schoolchildren with CF (age 7.2 $\pm 1.9 \mathrm{yrs}$ ). Chest radiographs were scored using five different CF scoring systems and Rint,exp measurements were expressed as height-adjusted Z-scores. Spirometry was assessed in schoolchildren and the results were expressed as a percentage of predicted values.

Chest radiograph scores worsened significantly over the 3-yr period and a tendency towards more pronounced changes was observed, especially for the Wisconsin score, in preschool children. Most preschool and schoolchildren had Rint,exp Z-scores within the normal range at start and follow-up, and the annual change in Rint,exp Z-score was not significant. In schoolchildren, only the forced expiratory volume in one second as a percentage of forced vital capacity declined significantly during the study period.

In summary, in young children with cystic fibrosis, chest radiograph scores worsen significantly over time even while lung function remains stable.

KEYWORDS: Chest radiograph scores, cystic fibrosis, interrupter resistance, preschool children

C hronic airway infection and inflammation in cystic fibrosis (CF) lung disease lead to structural lung damage, pulmonary dysfunction and, eventually, to respiratory insufficiency. CF lung disease starts at a very young age and, ideally, treatment should also start at, or even before, the onset of lung disease. Therefore, sensitive measures of structural and functional lung damage are needed to objectively assess lung disease progression and to evaluate the effect of treatment.

Structural lung damage in CF can be assessed by chest radiology and high-resolution computed tomography (HRCT) scanning. An annual chest radiograph and the use of chest radiograph scoring systems are recommended by the European CF Consensus Committee [1], and several different CF chest radiograph scoring systems [2-6] have been developed. In older children with moderate-to-severe $\mathrm{CF}$, there is good correlation between pulmonary function tests (PFTs), especially forced expiratory volume in one second (FEV1), and chest radiograph scores in cross-sectional studies $[4,6,7]$. Longitudinal evaluation of bronchopulmonary disease in children with CF using chest radiology showed disease progression from the age of $\sim 5$ yrs, even when spirometry results still remained stable [8-10]. However, in preschool children the sensitivity of chest radiographs as a measure of disease progression and the relationship with functional parameters is unclear.

Lung function can be assessed according to PFTs (especially spirometry) and, although FEV1 is still considered the gold standard in daily CF practice, peripheral flows such as mean forced expiratory flow between 25 and $75 \%$ of forced vital capacity (FEF25-75\%) seem more sensitive in young CF children [11] . Spirometry is feasible in most children aged 4-6 yrs, but standards for quality control are lacking for preschool children [12-14]. Therefore, alternative PFTs, such as the expiratory interrupter resistance (Rint,exp) measurement, have been developed for this age group [15-20]. Rint,exp measurements can be performed without sedation, are easily applicable in general practice, are effort-independent and reference values for children aged 3-13 yrs are available [18]. Rint,exp measurements may be of use in detecting early lung function abnormalities in children with CF. However, data on the value of interrupter resistance (Rint) measurements in CF patients are not conclusive $[12,17,18,20]$ and longitudinal measurements of Rint have never
AFFILIATIONS

Dept of Paediatric Pulmonology, University Medical Centre Utrecht, Utrecht, The Netherlands.

CORRESPONDENCE S.W.J. Terheggen-Lagro Dept of Paediatric Pulmonology University Medical Centre Utrecht Wilhelmina Children's Hospital Internal Postal Code KH 01.419.0 P.0. Box 85090

3508 AB Utrecht

The Netherlands

Fax: 31302504747

E-mail: s.terheggen@umcutrecht.nl

Received:

April 132006

Accepted after revision:

April 072007

\section{SUPPORT STATEMENT}

Financial support was provided by the Netherlands Organization for

Health Research and Development (ZonMW; The Hague, The Netherlands; grant 940-37-020)

STATEMENT OF INTEREST Statements of interest for H.G.M. Arets and C.K. van der Ent can be found at www.erj.ersjournals.com/ misc/statements.shtml 
been related to structural damage assessed by chest radiology.

The purpose of the present study was to evaluate the sensitivity of structural and functional parameters of lung disease progression in young children with CF. Disease progression in preschool (aged $<5 \mathrm{yrs}$ ) and schoolchildren (aged $>5 \mathrm{yrs}$ ) was studied prospectively using simple chest radiograph scores, Rint,exp measurements and spirometry.

\section{METHODS}

\section{Study population}

The Utrecht CF Centre of the University Medical Centre Utrecht (Utrecht, the Netherlands), a tertiary academic hospital, uses annual chest radiographs and PFT measurements, including spirometry and Rint,exp measurements, to monitor lung disease in patients with $\mathrm{CF}$.

A total of 21 preschool children and 30 schoolchildren who attended the CF Centre for their annual check-up between April 2002 and June 2003 were studied. A routine chest radiograph and a Rint,exp measurement were performed on the same day both that year and 3 yrs later. All schoolchildren performed spirometry at visits 1 and 2 . Measurements were performed when children were clinically stable. Informed consent was obtained from the parents of all participating children.

\section{Chest radiographs}

Chest radiographs (anteroposterior and lateral view) were blinded and scored in random order by two different observers (H.G.M. Arets and C.K. van der Ent) according to the following five cystic fibrosis chest radiograph scoring systems: ChrispinNorman scoring (range 0-38, with 0 as the best score) [2]; adjusted Chrispin-Norman scoring (range $0-42$, with 0 as the best score) [3]; Wisconsin scoring (range 0-100, with 0 as the best score) [4]; Northern scoring (range 0-20, with 0 as the best score) [5]; and Brasfield (Birmingham) scoring system (range 4-25, with 25 as the best score) [6].The systems score different abnormalities, such as hyperinflation, linear markings, nodular cystic lesions and large lesions (segmental or lobar atelectasis or consolidation). In order to establish intra-observer variability, both observers randomly scored eight chest radiographs for a second time after 3 months. Prior to assessment it was agreed that a cut-off value of 5 for the Wisconsin score and 21 for the Brasfield score would be associated with mild, but potentially irreversible, lung damage [10].

\section{Rint,exp and spirometry}

Airway resistance was measured in all children using the MicroRint ${ }^{\circledR}$ (Micro Medical Ltd, Chatham, UK), as described in previous studies $[15,16,19]$. A successful Rint,exp measurement consisted of the median Rint,exp value of at least five out of 10 interruptions. Rint,exp was calculated using the back extrapolation technique to $\mathrm{t}=0 \mathrm{~ms}$ after shutter closure during $100 \mathrm{~ms}$ $[15,21]$. Rint,exp values in children with CF were expressed as height-adjusted Z-scores, using data from a Dutch healthy control population [19].

All schoolchildren performed spirometry at visits 1 and 2 (Masterlab, Hochberg, Germany). Spirometry results were obtained for FEV1, forced vital capacity (FVC), maximal instantaneous forced flow when $50 \%$ of the FVC remains to be exhaled (MEF50\%), forced expiratory flow at 75\% of FVC and FEF25-75\%. These results were expressed as a percentage of predicted values using data from ZAPLETAL [22]. FEV1 was also expressed as a percentage of FVC (FEV1/FVC). Abnormal lung function was defined as an FEV1 $<85 \%$ pred.

\section{Lung structure and lung function over time}

The average of the chest radiograph scores from the two observers was used. Data obtained at the first visit are reported as chest radiograph1, Rint,exp Z-score1 and PFT1, and at the second visit as chest radiograph2, Rint,exp Z-score2 and PFT2. $\Delta$ chest radiograph is the annual change for a chest radiograph scoring system (chest radiograph2-chest radiograph1/time interval); $\Delta$ Rint,exp Z-score is the annual change for Rint,exp Zscore (Rint,exp Z-score2-Rint,exp Z-score1/time interval); and $\triangle \mathrm{PFT}$ is the annual change for PFTs (PFT2-PFT1/time interval). To compare the annual changes of the five chest radiograph scoring systems, $\Delta$ chest radiograph was also expressed as a percentage of the maximal obtainable score for that system except for the Brasfield scoring system, since the best score for this system is 25 and the worst score is 4 . A positive value for $\Delta$ chest radiograph indicates an increase in structural abnormalities for all chest radiograph scoring systems except for the Brasfield scoring system, where a negative value for $\Delta$ chest radiograph indicates an increase in structural abnormalities. A positive value for $\Delta R$ int,exp Z-score indicates an increase in resistance and thus a worsening of lung function. A negative value for $\triangle \mathrm{PFT}$ indicates a decline in lung function.

\section{Statistical analysis}

Intra- and interobserver variability of composite chest radiograph scores was calculated using intraclass correlation coefficients. To determine whether chest radiograph scores and/or Rint,exp Z-score and/or PFTs changed significantly over time in preschool and in schoolchildren, paired t-tests were performed for $\Delta$ Rint,exp Z-score, $\Delta \mathrm{PFT}$ and $\Delta$ chest radiograph. Mean differences between the parameters at visits 1 and 2 were expressed as the mean annual decline, calculated by dividing the mean difference by the time interval. The relationships between chest radiographs, Rint,exp Z-scores and PFTs, and between $\Delta$ chest radiograph, $\Delta R$ int,exp $Z$-score and $\Delta \mathrm{PFT}$ were evaluated using Spearman correlation coefficients. Finally, changes in chest radiograph scores and Rint,exp Z-score over time were compared between preschool and schoolchildren using SAS PROC mixed models. A p-value $<0.05$ was considered to be statistically significant. Data are presented as mean \pm SD.

\section{RESULTS}

\section{Study population}

Characteristics of the preschool and schoolchildren are shown in table 1. Mild, but potentially irreversible lung damage (Wisconsin score $>5$, Brasfield score $<21$ ) was found at visit 1 in: five $(24 \%)$ of the 21 preschool children for the Wisconsin score; seven $(33 \%)$ of the 21 preschool children for the Brasfield score; 12 (40\%) of the 30 schoolchildren for the Wisconsin score; and $15(50 \%)$ of the 30 schoolchildren for the Brasfield score.

Most preschool children had Rint,exp Z-scores that were within normal range (mean $\pm 2 \times Z$-scores) both at visit 1 (9.5\% had a Rint,exp Z-score $>2 \times \mathrm{SD})$ and at visit $2(19 \%$ had a Rint,exp Z-score $>2 \times \mathrm{SD}$ ). In schoolchildren, $13 \%$ had a Rint,exp Z-score $>2 \times$ SD at visit 1 and $23 \%$ at visit 2 (figs. $1 \mathrm{a}$ and $1 \mathrm{~b}$ ). Only 


\begin{tabular}{|c|c|c|c|c|}
\hline \multirow[t]{3}{*}{ TABLE 1} & $\begin{array}{l}\text { haracteristi } \\
\text { ildren }{ }^{\circledR} \text { with }\end{array}$ & $\begin{array}{l}\text { s of the pr } \\
\text { cystic fibro }\end{array}$ & $\begin{array}{l}\text { reschool } \\
\text { osis at visits }\end{array}$ & $\begin{array}{l}\text { and } \\
\text { s } 1 \text { and } 2\end{array}$ \\
\hline & \multicolumn{2}{|c|}{ Preschool children } & \multicolumn{2}{|c|}{ Schoolchildren } \\
\hline & Visit 1 & Visit 2 & Visit 1 & Visit 2 \\
\hline Age yrs & $3.2 \pm 0.9$ & $6.0 \pm 1.1$ & $7.2 \pm 1.9$ & $10.1 \pm 1.9$ \\
\hline Male/female sex & $9 / 12$ & $9 / 12$ & $16 / 14$ & $16 / 14$ \\
\hline Height m & $0.95 \pm 0.09$ & $1.14 \pm 0.09$ & $1.24 \pm 0.12$ & $1.40 \pm 0.12$ \\
\hline Height SDS & $-0.92 \pm 1.13$ & $-0.93 \pm 1.0$ & $-0.40 \pm 0.80$ & $-0.56 \pm 0.87$ \\
\hline Weight kg & $14.0 \pm 2.2$ & $19.1 \pm 3.3$ & $24.3 \pm 5.9$ & $32.3 \pm 7.6$ \\
\hline \multicolumn{5}{|l|}{ Genotype } \\
\hline$\Delta \mathrm{F} 508$ homozygous $\mathrm{n}$ & 12 & & 20 & \\
\hline$\Delta \mathrm{F} 508$ heterozygous $\mathrm{n}$ & 9 & & 8 & \\
\hline Other $n$ & 0 & & 2 & \\
\hline \multicolumn{5}{|l|}{ Presenting symptoms $^{+}$} \\
\hline Meconium ileus $n$ & 2 & & 1 & \\
\hline Malabsorption n & 17 & & 25 & \\
\hline Respiratory symptoms $n$ & 13 & & 18 & \\
\hline \multicolumn{5}{|l|}{ PFTs } \\
\hline Rint,exp Z-score & $0.14 \pm 1.1$ & $0.16 \pm 1.4$ & $0.64 \pm 1.4$ & $0.75 \pm 1.4$ \\
\hline FEV1 \% pred & & $103.4 \pm 22.9$ & $95.1 \pm 16.3$ & $90.1 \pm 15.4$ \\
\hline FVC \% pred & & $99.4 \pm 17.3$ & $92.4 \pm 14.8$ & $92.9 \pm 9.3$ \\
\hline FEV $1 / F V C$ & & $89.2 \pm 8.4$ & $88.2 \pm 7.7$ & $82.0 \pm 9.3$ \\
\hline MEF50\% \% pred & & $79.8 \pm 30.4$ & $72.9 \pm 27.1$ & $71.3 \pm 26.3$ \\
\hline FEF75\% \% pred & & $69.1 \pm 40.6$ & $59.5 \pm 30.8$ & $51.1 \pm 29.7$ \\
\hline FEF $25-75 \% \%$ pred & & $79.2 \pm 32.7$ & $72.1 \pm 29.3$ & $66.5 \pm 27.4$ \\
\hline \multicolumn{5}{|l|}{ Radiograph scores } \\
\hline Chrispin-Norman & $8.7 \pm 4.4$ & $11.0 \pm 2.5$ & $10.1 \pm 3.2$ & $11.4 \pm 3.5$ \\
\hline $\begin{array}{l}\text { Adjusted Chrispin- } \\
\text { Norman }\end{array}$ & $9.8 \pm 4.9$ & $12.8 \pm 2.6$ & $11.5 \pm 3.3$ & $13.2 \pm 3.6$ \\
\hline Wisconsin & $3.6 \pm 1.9$ & $4.5 \pm 1.6$ & $4.4 \pm 1.7$ & $4.5 \pm 1.7$ \\
\hline Northern & $5.1 \pm 2.1$ & $6.1 \pm 2.0$ & $6.0 \pm 1.7$ & $6.4 \pm 1.9$ \\
\hline Brasfield & $20.4 \pm 1.7$ & $18.7 \pm 1.5$ & $19.6 \pm 1.6$ & $19.1 \pm 2.0$ \\
\hline
\end{tabular}

Data are presented as mean \pm SD, unless otherwise stated. SDS: standard deviation score; PFTs: pulmonary function tests; Rint,exp: expiratory interrupter resistance; FEV1: forced expiratory volume in 1 second; \% pred: \% predicted; FVC: forced vital capacity; MEF50\%: maximal instantaneous forced flow when $50 \%$ of the FVC remains to be exhaled; FEF75\%: forced expiratory flow at $75 \%$ of FVC; FEF25-75\%: forced expiratory flow between 25 and $75 \%$ of FVC. ${ }^{*}: n=21$; $\because: n=30 ;{ }^{+}$: some children presented with more than one symptom.

seven $(23 \%)$ of the 30 schoolchildren had abnormal lung function $(\mathrm{FEV} 1<85 \%)$ at visit 1 .

\section{Reproducibility of the scoring systems}

Intraclass correlation coefficients ( $r$-values) between both observers for the different scoring systems were moderate $(\mathrm{r}$ ranging $0.60-0.65)$. Intraclass correlation coefficients for intraobserver variability were moderate to good (H.G.M. Arets varying from $r=0.57$ for the Northern scoring system to $r=0.88$ for the adjusted Chrispin-Norman scoring system, and C.K. van der Ent varying from $\mathrm{r}=0.78$ for the adjusted Chrispin-Norman scoring system to $\mathrm{r}=0.91$ for the Wisconsin scoring system).

\section{Lung structure over time}

All chest radiograph scores except the Northern score worsened significantly over time in preschool children $(\mathrm{p}<0.05$ for the Wisconsin score and $\mathrm{p}<0.001$ for all the other scores; table 2). Figure 2 shows the changes in ChrispinNorman score with increasing age. There was no statistically significant difference in change in Chrispin-Norman score over time between preschool and schoolchildren (fig. 2). The mean changes in radiograph scores expressed as a percentage of the maximal scores in preschool children were 2.2, 2.6, 0.4 and $1.7 \% \cdot \mathrm{yr}^{-1}$ for Chrispin-Norman, adjusted ChrispinNorman, Wisconsin and Northern, respectively. In schoolchildren, only the Chrispin-Norman and adjusted ChrispinNorman scores worsened significantly over time (table 2). The mean changes in radiograph scores expressed as a percentage of the maximal scores in schoolchildren were 1.3, 1.5, 0.0 and $0.5 \% \cdot \mathrm{yr}^{-1}$ for Chrispin-Norman, adjusted Chrispin-Norman, Wisconsin and Northern, respectively. Preschool children showed a tendency towards more pronounced changes in chest radiograph scores over time, but this was only statistically significant for the Wisconsin score $(p=0.04)$. Individual progression of lung disease over time scored according to the Chrispin-Norman score is illustrated in figure 3 .

\section{Lung function over time}

Rint,exp Z-scores did not change significantly over time in preschool and schoolchildren. Changes in Rint,exp Z-scores were also assessed in CF patients with no, or only mild signs of, pulmonary hyperinflation on their chest radiograph. Only 15 children showed no or only mild hyperinflation. The difference in progression of Rint,exp Z-score between children with no or only mild hyperinflation versus moderate-to-severe hyperinflation was $0.02 \pm 0.92$ versus $0.37 \pm 1.6(p=0.51)$. When comparing preschool children with schoolchildren, Rint,exp Zscores appeared higher in schoolchildren but this difference was not statistically significant.

In schoolchildren, only FEV1/FVC worsened significantly over time (annual decline $1.94 \% ; \mathrm{p}<0.01$ ). Individual changes in FEV1/FVC were plotted versus age over time for all schoolchildren and eight preschool children that were able to perform spirometry at both visits, as shown in figure 4 .

\section{Correlation between lung structure and lung function}

In preschool children, there was no significant correlation between chest radiograph and Rint,exp Z-score at visits 1 and 2 at cross-sectional data analysis. Longitudinal data analysis also showed no significant correlation between $\Delta$ chest radiograph scores and $\Delta R$ int,exp Z-score. In schoolchildren, no significant correlation was found between chest radiograph and Rint,exp Zscore at visits 1 and 2, or between chest radiograph and PFT at visit 1. There was, however, a significant but moderate correlation between the Chrispin-Norman and adjusted Chrispin-Norman scores and FEV1, MEF50\%, FEF25-75\% and FEV1/FVC at visit 2. The Wisconsin score correlated significantly but weakly with FEV1, FEV1/FVC and FEF25-75\% and the Brasfield score correlated significantly but weakly with FEV1 and MEF25-75\% at visit 2.

\section{DISCUSSION}

In the present study the capability of chest radiograph scores, Rint,exp measurements and spirometry to detect and monitor progression of lung damage in young children with CF was evaluated. Chest radiograph scores worsened significantly 

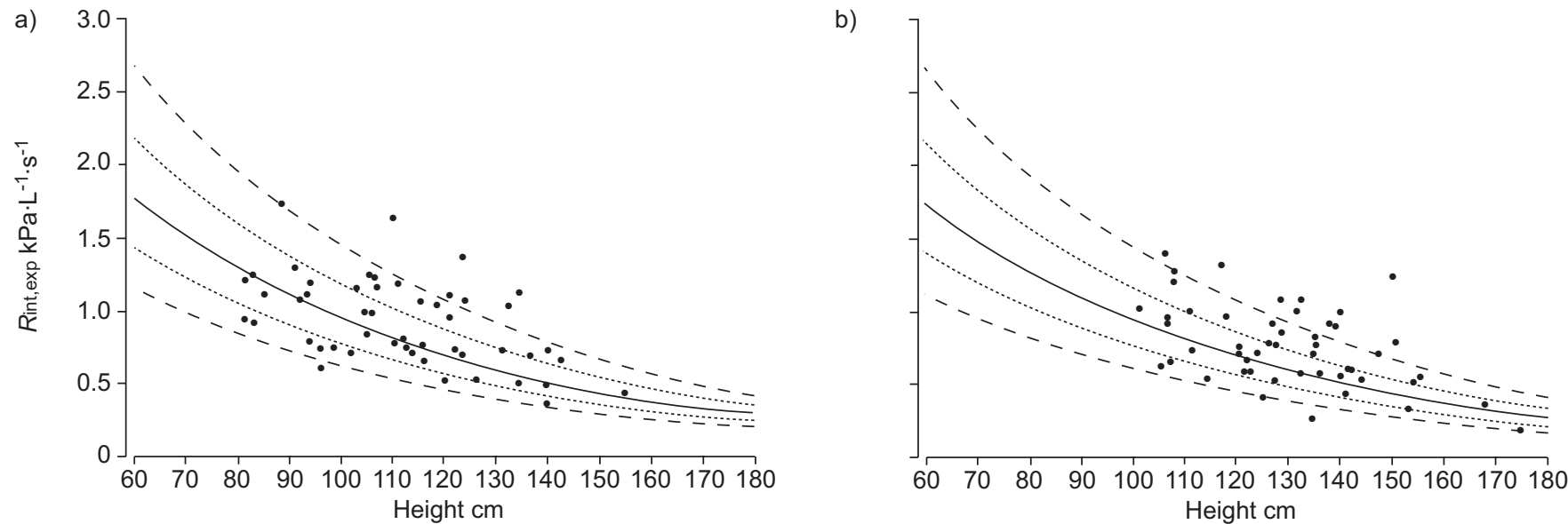

FIGURE 1. Absolute expiratory interrupter resistance (Rint,exp) values in preschool and schoolchildren with cystic fibrosis compared with the regression line ( - 10 log Rint,exp $=0.645-0.00668 \times$ standing height (in $\mathrm{cm}$ ), showing \pm Z-score $(\cdots \cdot)$ and $\pm 2 \times Z$-score lines $(----)$ ) of the Dutch healthy control group at a) visit 1 and b) visit 2

over a 3-yr period in both preschool and schoolchildren. In the study group, the annual changes for the Wisconsin score were less than those observed in the large Wisconsin trial cohort previously described elsewhere [8]. Comparisons are hampered by the fact that the Wisconsin trial group was subdivided into four groups: screened, nonscreened and patients with or without Pseudomonas aeruginosa. Besides differences between the Wisconsin trial and the present study in the number of children included and the duration of followup, the time of inclusion was also different. In the Wisconsin trial, children from the period 1985-1998 were included. In recent years, major changes in the detection techniques and treatment regimen for $P$. aeruginosa have been implemented in daily CF care, making comparison of the present cohort with the Wisconsin trial cohort more difficult. In the present cohort, five preschool children and six schoolchildren had a positive sputum culture with $P$. aeruginosa at visit 1 . These children did not show faster progression than the children without $P$. aeruginosa. In the Wisconsin trial, however, children who acquired $P$. aeruginosa at a young age showed marked

\section{TABLE 2 Mean annual change for different parameters in preschool ${ }^{\#}$ and schoolchildren}

\begin{tabular}{|c|c|c|c|c|}
\hline & \multicolumn{2}{|c|}{ Preschool children } & \multicolumn{2}{|c|}{ Schoolchildren } \\
\hline & Mean annual change & $p$-value & Mean annual change & p-value \\
\hline Interval $^{+}$yrs & 2.76 & & 2.89 & \\
\hline Height $\mathrm{m}$ & 0.070 & 0.000 & 0.055 & 0.000 \\
\hline Weight kg & 2.84 & 0.000 & 2.71 & 0.000 \\
\hline FEV $1 \%$ pred & & & -1.62 & 0.125 \\
\hline FVC \% pred & & & 0.05 & 0.956 \\
\hline $\mathrm{FEV}_{1} / \mathrm{FVC}$ & & & -1.94 & 0.001 \\
\hline MEF50\% \% pred & & & -1.20 & 0.518 \\
\hline FEF75\% \% pred & & & -2.72 & 0.14 \\
\hline Wisconsin & 0.35 & 0.031 & 0.03 & 0.977 \\
\hline Northern & 0.33 & 0.110 & 0.11 & 0.34 \\
\hline Brasfield & -0.60 & 0.001 & -0.21 & 0.081 \\
\hline
\end{tabular}

PFTs: pulmonary function tests; Rint,exp: expiratory interrupter resistance; FEV1: forced expiratory volume in one second; \% pred: \% predicted; FVC: forced vital capacity; MEF50\%: maximal instantaneous forced flow when $50 \%$ of the FVC remains to be exhaled; FEF $75 \%$ : forced expiratory flow at $75 \%$ of FVC; FEF $25-75 \%$ : forced expiratory flow between 25 and $75 \%$ of FVC. ${ }^{\#:} \mathrm{n}=21 ; \because \mathrm{n}=30$; ${ }^{+}$: interval represents the mean time between visits 1 and 2 . 


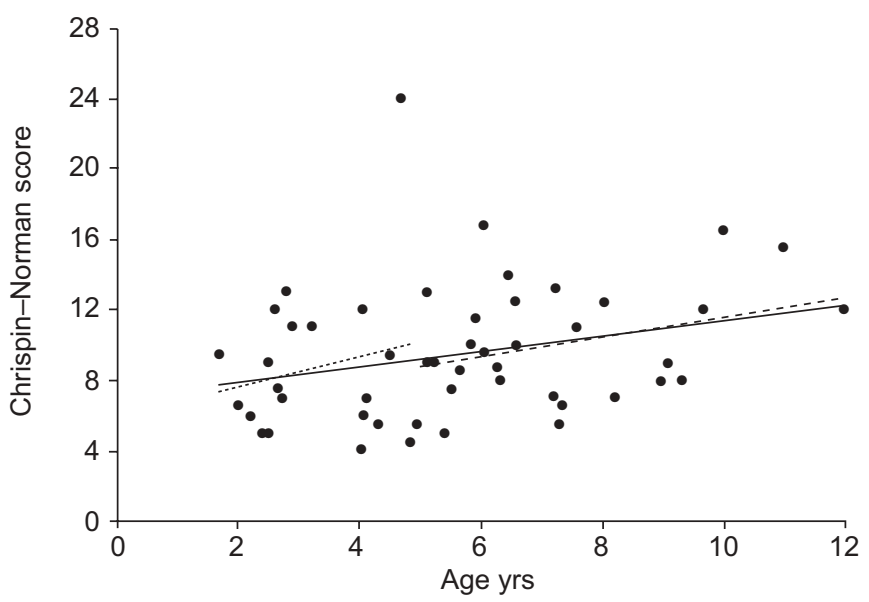

FIGURE 2. Chrispin-Norman score plotted against age for the whole group at visit 1. Slopes are shown for the group as a whole $(-)$ and for both preschool $(\cdots \cdot \cdot)$ and schoolchildren (----). The regression equation for the group as a whole was $y=0.445 x+7.02$

progression of the Wisconsin chest radiograph scores after the age of 10 yrs. Follow-up in the present cohort is too short to come to the same conclusion.

Preschool children showed a tendency towards a faster decline in chest radiograph scores than schoolchildren and this difference was statistically significant for the Wisconsin score. The Chrispin-Norman and adjusted Chrispin-Norman scores showed the greatest annual decline in both preschool and schoolchildren. Conversely, Wisconsin, Northern and Brasfield scores did not change significantly in schoolchildren. At inclusion, $24-33 \%$ of preschool children and $40-50 \%$ of schoolchildren already had a chest radiograph score that resembled mild but potentially irreversible lung damage [10]. In the present study, radiograph scores were more sensitive to monitor disease progression than functional parameters, especially in young children. This suggests that chest radiographs can be helpful in the follow-up of CF lung disease progression in young children. Chest radiographs can sensitively measure changes from normality to mild lung disease and these changes already appear in preschool children. The schoolchildren scored in the present study had normal lung function both at visits 1 and 2. In schoolchildren, bronchiectasis became an important morphological change and HRCT of the chest is considered the gold standard for diagnosing bronchiectasis [23]. This might, in part, explain why in the present study chest radiograph scores in schoolchildren showed less progression over the 3 -yr period than the scores in preschool children.

One of the drawbacks of using CF chest radiograph scores is that the interpretation of the abnormalities seen on a chest radiograph is not always straightforward. For example, increased densities can be interpreted in various ways and this can cause greater interobserver variability of scores. Intraand interobserver variability of the chest radiograph scores used in the present study was moderate to good. The use of HRCT of the chest has been advocated for several years, since HRCT seems to be more sensitive than chest radiographs in

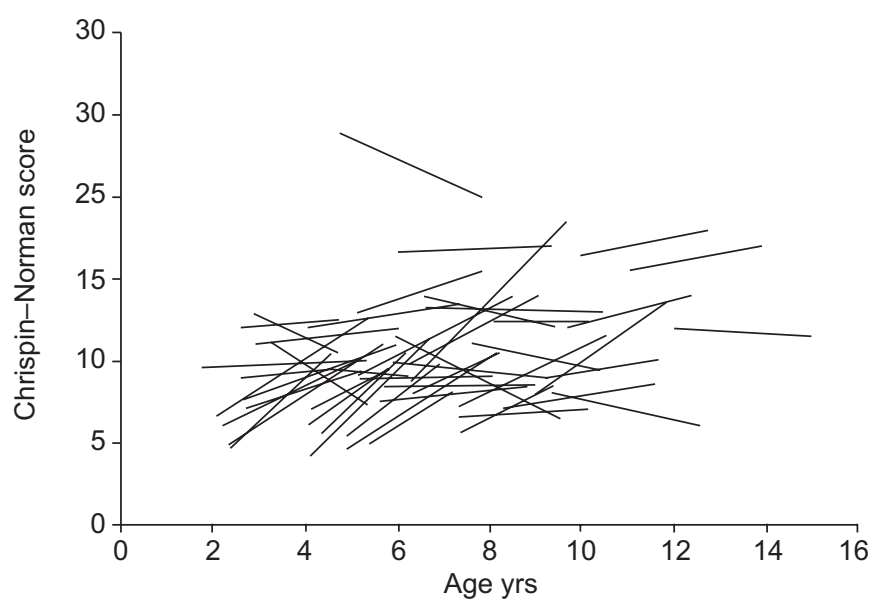

FIGURE 3. Individual changes in Chrispin-Norman score versus age at both visits. The regression equation was Chrispin-Norman score at visit $2=$ $0.51 \times($ Chrispin-Norman score at visit 1)+6.36.

detecting structural abnormalities in children with mild $\mathrm{CF}$ [24-26]. Even in young children and infants with CF, HRCT can detect structural abnormalities [27, 28]. Several crosssectional studies showed good correlation between HRCT scores and chest radiograph scores [24, 25, 29]. Although HRCT is sensitive in detecting structural abnormalities [27], especially in young patients, implementation of sequential HRCT scanning into daily CF care is hampered by several factors. HRCT of the chest causes higher radiation dosage and a subsequent higher risk for cancer compared with chest radiographs [30]. It is more expensive and, although scan time of modern scanners has become so short that images can be obtained while the child is spontaneously breathing, HRCT in very young children still requires sedation. Studies comparing changes in HRCT scores with changes in chest radiograph scores in children over a longer period of time are lacking. In the present study it is shown that chest radiograph scores

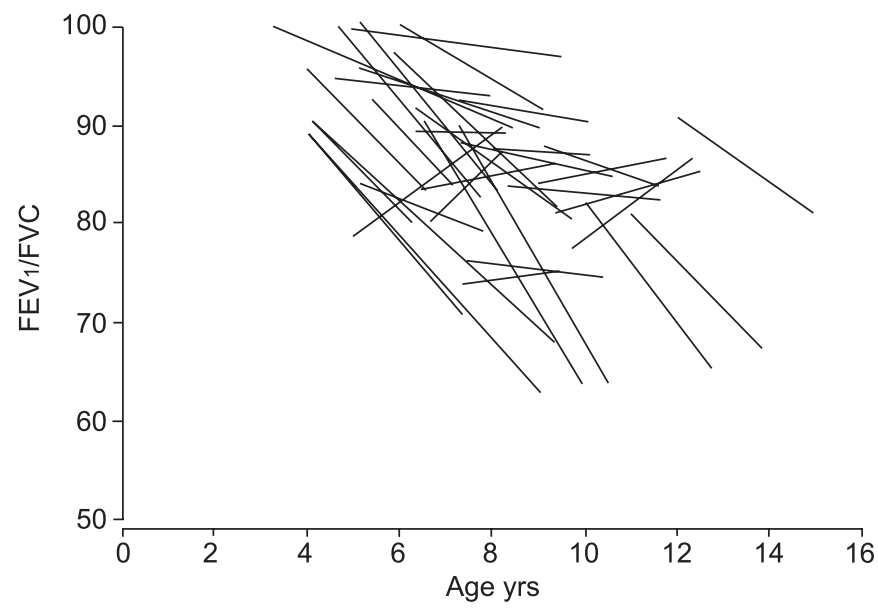

FIGURE 4. Individual changes in forced expiratory volume in one second as a percentage of forced vital capacity (FEV $1 / F V C)$ over time for 30 schoolchildren and eight preschool children. The mean/average regression equation was $\mathrm{FEV}_{1} / \mathrm{FVC}$ at visit $2=0.553 \times\left(\mathrm{FEV}_{1} / \mathrm{FVC}\right.$ at visit 1$)+33.38$ 
worsen in both preschool and schoolchildren while lung function remains stable. Considering these results and the current limitations in the implementation of HRCT scanning in daily CF care, there still seems to be a valuable role for chest radiograph scores in monitoring structural lung damage in daily clinical practice and possibly in long-term clinical trials, especially since the radiation burden is reduced even further by excluding the lateral film [31]. Radiation burden and the increased risk of cancer related to repeated HRCT scans compared with chest radiographs should remain a topic of discussion, since survival in CF has increased significantly over time.

Despite significant abnormalities of chest radiograph scores, most preschool and schoolchildren had a Rint,exp Z-score within the normal range both at visits 1 and 2, and the annual change in Rint,exp Z-score was not significant. These findings suggest that Rint,exp measurements do not sensitively discriminate between children with CF and healthy children, and that longitudinal evaluation of Rint,exp measurements are not sensitive enough to detect early progression of lung disease in $\mathrm{CF}$. The between-occasion repeatability of Rint is poor and the variation in bronchial tone is high, limiting the usefulness of repeated $R$ int,exp measurements in monitoring disease progression in CF [32]. Furthermore, most patients in the present study had signs of hyperinflation, as was established according to their chest radiograph. CF patients with pulmonary hyperinflation can compensate by elevating their resting endexpiratory level, a pathophysiological feature that is not recognised by Rint measurements. In accordance with the present results, no consistent abnormal levels or increases in Rint were found in a 4 -yr prospective study of inspiratory respiratory resistance measured according to the interrupter technique in young children with CF [20].

No correlation was found between structural damage assessed by chest radiograph scores and lung function at visit 1 . This is not surprising at all since correlations between functional features and structural alterations of a common origin would not be expected. It would be interesting to compare, for example, pulmonary hyperinflation with functional residual capacity, or nodular cystic lesions with gas exchange. These comparisons are complicated by the fact that most of the children included in the present study were too young to perform PFTs other than Rint measurements and spirometry. Progression of Rint,exp Z-score was compared between children with no or mild signs of hyperinflation on their chest radiograph and children with moderate-to-severe hyperinflation, but no statistically significant difference was found. In schoolchildren no correlation was found between chest radiograph scores and spirometry at visit 1 ; however, a moderate but significant correlation was observed between most chest radiograph scores and spirometry at visit 2 . One possible explanation for the moderate but significant correlation between chest radiograph scores and spirometry at visit 2 is that at visit 2 a larger proportion of children had a FEV1 $<85 \%$ pred, suggesting more advanced lung disease and, consequently, a better correlation with structural abnormalities, as has been shown previously [7]. Other possibilities include a higher inflation level when the chest radiograph was taken and improved technical abilities due to their older age.
Longitudinal analysis of PFT decline in schoolchildren showed no statistically significant worsening except for FEV1/FVC. A significant change in FEV1/FVC ratio (expressed as Z-score) has been described previously by DE JONG et al. [33] in a larger group of older children with CF. In a different study by $\mathrm{DE}$ JONG et al. [27] no significant annual decline in \% pred values of FEV1/FVC ratio was described. Significant but slow deterioration of FEV1/FVC \% pred ratio was, however, described in a longitudinal study assessing effect of mucoid $P$. aeruginosa infection on lung disease progression [9]. Whether the FEV1/ FVC ratio is a sensitive measure in detecting early and mild lung disease in $\mathrm{CF}$ remains to be answered, since neither \% pred nor FEV1/FVC ratio Z-score is usually considered a primary end-point in CF trials. Depending on the stage of lung disease, different spirometric parameters have different sensitivities in detecting changes [34]. FEV1/FVC might thus be a more sensitive spirometric parameter in early CF lung disease than FEV1 and should be included as an end-point in clinical trials in early CF lung disease.

In conclusion, the present study shows that there is a significant annual deterioration of routine chest radiograph scores in young children, especially in preschool children. A proportion of preschool children already have abnormal chest radiographs, while expiratory interrupter resistance Z-scores are within the normal range in most children with cystic fibrosis. Expiratory interrupter resistance is not a good measure with which to monitor pulmonary disease progression in groups of children with cystic fibrosis. Spirometry (except for forced expiratory volume in one second as a percentage of forced vital capacity) in schoolchildren remained stable in the studied group and correlated only moderately with chest radiographs. Therefore, radiograph scores represent a more sensitive measure than pulmonary function tests to evaluate lung disease progression in young children with mild cystic fibrosis lung disease.

\section{ACKNOWLEDGEMENTS}

The authors would like to thank I. Prins and J. Tersmette (Dept of Paediatric Pulmonology, University Medical Centre Utrecht, Utrecht, the Netherlands) for performing all interrupter resistance measurements.

\section{REFERENCES}

1 Kerem E, Conway S, Elborn S, Heijerman H, Consensus Committee. Standards of care for patients with cystic fibrosis: a European consensus. J Cyst Fibros 2005; 4: 7-26.

2 Chrispin AR, Norman AP. The systematic evaluation of the chest radiograph in cystic fibrosis. Pediatr Radiol 1974; 2: 101-105.

3 van der Put JM, Meradji M, Danoesastro D, Kerrebijn KF. Chest radiographs in cystic fibrosis. A follow-up study with application of a quantitative scoring system. Pediatr Radiol 1982; 12: 57-61.

4 Weatherly MR, Palmer CG, Peters ME, et al. Wisconsin cystic fibrosis chest radiograph scoring system. Pediatrics 1993; 91: 488-495.

5 Conway SP, Pond MN, Bowler I, et al. The chest radiograph in cystic fibrosis: a new scoring system compared with the Chrispin-Norman and Brasfield scores. Thorax 1994; 49: 860-862. 
6 Brasfield D, Hicks G, Soong S, Tiller RE. The chest roentgenogram in cystic fibrosis: a new scoring system. Pediatrics 1979; 63: 24-29.

7 Terheggen-Lagro SWJ, Truijens N, van Poppel N, Gulmans V, van der Laag J, van der Ent C. Correlation of six different cystic fibrosis chest radiograph scoring systems with clinical parameters. Pediatr Pulmonol 2003; 35: 441-445.

8 Farrell PM, Li Z, Kosorok MR, et al. Bronchopulmonary disease in children with cystic fibrosis after early or delayed diagnosis. Am J Respir Crit Care Med 2003; 168: 1100-1108.

$9 \mathrm{Li} \mathrm{Z,} \mathrm{Kosorok} \mathrm{MR,} \mathrm{Farrell} \mathrm{PM,} \mathrm{et} \mathrm{al.} \mathrm{Longitudinal}$ development of mucoid Pseudomonas aeruginosa infection and lung disease progression in children with cystic fibrosis. JAMA 2005; 293: 581-588.

10 Farrell PM, Li Z, Kosorok MR, et al. Longitudinal evaluation of bronchopulmonary disease in children with cystic fibrosis. Pediatr Pulmonol 2003; 36: 230-240.

11 Quan JM, Tiddens HA, Sy JP, et al. A two-year randomized, placebo-controlled trial of dornase alfa in young patients with cystic fibrosis with mild lung function abnormalities. J Pediatr 2001; 139: 813-820.

12 Beydon N, Amsallem F, Bellet M, et al. Pulmonary function tests in preschool children with cystic fibrosis. Am J Respir Crit Care Med 2002; 166: 1099-1104.

13 Aurora P, Stocks J, Oliver C, et al. Quality control for spirometry in preschool children with and without lung disease. Am J Respir Crit Care Med 2004; 169: 1152-1159.

14 Arets HG, Brackel HJ, van der Ent CK. Forced expiratory manoeuvres in children: do they meet the ATS and ERS criteria for spirometry? Eur Respir J 2001; 18: 655-660.

15 Merkus PJ, Mijnsbergen JY, Hop WC, de Jongste JC. Interrupter resistance in preschool children: measurement characteristics and reference values. Am J Respir Crit Care Med 2001; 163: 1350-1355.

16 Arets HG, Brackel HJ, van der Ent CK. Applicability of interrupter resistance measurements using the MicroRint in daily practice. Respir Med 2003; 97: 366-374.

17 Oswald-Mammosser M, Charloux A, Donato L, et al. Interrupter technique versus plethysmography for measurement of respiratory resistance in children with asthma or cystic fibrosis. Pediatr Pulmonol 2000; 29: 213-220.

18 Carter ER, Stecenko AA, Pollock BH, Jaeger MJ. Evaluation of the interrupter technique for the use of assessing airway obstruction in children. Pediatr Pulmonol 1994; 17: 211-217.

19 Merkus PJFM, Arets HGM, Joosten T, et al. Measurements of interrupter resistance: reference values for children 3-13 yrs of age. Eur Respir J 2002; 20: 907-911.

20 Nielsen KG, Pressler T, Klug B, Koch C, Bisgaard H. Serial lung function and responsiveness in cystic fibrosis during early childhood. Am J Respir Crit Care Med 2004; 169: 1209-1216.
21 Phagoo SB, Wilson NM, Silverman M. Evaluation of a new interrupter device for measuring bronchial responsiveness and the response to bronchodilator in 3 year old children. Eur Respir J 1996; 9: 1374-1380.

22 Zapletal A. Lung function in children and adolescents. Methods, reference values. In: Zapletal A, Samanek M, Paul T, eds. Progress in Respiration Research. Basel, S Karger AG, 1987; pp. 114-218.

23 Munro NC, Cooke JC, Currie DC, Strickland B, Cole PJ. Comparison of thin section computed tomography with bronchography for identifying bronchiectatic segments in patients with chronic sputum production. Thorax 1990; 45: 135-139.

24 Santamaria F, Grillo G, Guidi G, et al. Cystic fibrosis: when should high-resolution computed tomography of the chest be obtained? Pediatrics 1998; 101: 908-913.

25 Demirkazik FB, Ariyürek OM, Özçelik U, Göçmen A, Hassanabad HK, Kiper N. High resolution CT in children with cystic fibrosis: correlation with pulmonary functions and radiographic scores. Eur J Radiol 2001; 37: 54-59.

26 Nasr SZ, Kuhns LR, Brown RW, Hurwitz ME, Sanders GM, Strouse PJ. Use of computerized tomography and chest $X$ rays in evaluating efficacy of aerosolized recombinant human DNase in cystic fibrosis patients younger than age 5 years: a preliminary study. Pediatr Pulmonol 2001; 31: 377-382.

27 de Jong PA, Nakano Y, Lequin $\mathrm{MH}$, et al. Progressive damage on high resolution computed tomography despite stable lung function in cystic fibrosis. Eur Respir J 2004; 23: 93-97.

28 Long FR, Williams RS, Castile RG. Structural airway abnormalities in infants and young children with cystic fibrosis. J Pediatr 2004; 144: 154-161.

29 Maffessanti M, Candusso M, Brizzi F, Piovesana F. Cystic fibrosis in children: HRCT findings and distribution of disease. J Thorac Imaging 1996; 11: 27-38.

30 Berrington de Gonzalez A, Samet JM. What are the cancer risks from using chest computed tomography to manage cystic fibrosis? Am J Respir Crit Care Med 2006; 173: 139-140.

31 Benden C, Wallis C, Owens CM, Ridout DA, Dinwiddie R. The Chrispin-Norman score in cystic fibrosis: doing away with the lateral view. Eur Respir J 2005; 26: 894-897.

32 Child F. The measurement of airways resistance using the interrupter technique (Rint). Paediatr Respir Rev 2005; 6: 273-277.

33 de Jong PA, Lindblad A, Rubin L, et al. Progression of lung disease on computed tomography and pulmonary function tests in children and adults with cystic fibrosis. Thorax 2006; 61: 80-85.

34 Tiddens HA. Detecting early structural lung damage in cystic fibrosis. Pediatr Pulmonol 2002; 34: 228-231. 